OPEN ACCESS

Edited by:

Bisheng Zhou,

University of Illinois at Chicago,

United States

Reviewed by:

Xingrong Du,

Fudan University, China

Jiaxiang Chen,

Mayo Clinic Comprehensive Cancer

Center, United States

${ }^{*}$ Correspondence:

Giuseppe Derosa

giuseppe.derosa@unipv.it

Specialty section: This article was submitted to Nutritional Immunology, a section of the journal

Frontiers in Immunology

Received: 29 July 2020

Accepted: 14 June 2021

Published: 28 June 2021

Citation:

Derosa G, Maffioli P, D'Angelo A and Di Pierro F (2021) Nutraceutical

Approach to Preventing

Coronavirus Disease 2019 and Related Complications.

Front. Immunol. 12:582556. doi: 10.3389/fimmu.2021.582556

\section{Nutraceutical Approach to Preventing Coronavirus Disease 2019 and Related Complications}

\author{
Giuseppe Derosa ${ }^{1,2^{\star}}$, Pamela Maffioli ${ }^{1}$, Angela D'Angelo ${ }^{2}$ and Francesco Di Pierro ${ }^{3,4}$ \\ ${ }^{1}$ Department of Internal Medicine and Therapeutics, University of Pavia, Pavia, Italy, ${ }^{2}$ Laboratory of Molecular Medicine, \\ University of Pavia, Pavia, Italy, ${ }^{3}$ Velleja Research S.r.I., Milan, Italy, ${ }^{4}$ Digestive Endoscopy \& Gastroenterology, \\ Poliambulanza Hospital, Brescia, Italy
}

Introduction: Several months ago, Chinese authorities identified an atypical pneumonia in Wuhan city, province of Hubei (China) caused by a novel coronavirus (2019-nCoV or SARS-CoV-2). The WHO announced this new disease was to be known as "COVID-19".

Evidence Acquisition: Several approaches are currently underway for the treatment of this disease, but a specific cure remains to be established.

Evidence Synthesis: This review will describe how the use of selected nutraceuticals could be helpful, in addition to pharmacological therapy, in preventing some COVID-19related complications in infected patients.

Conclusions: Even if a specific and effective cure for COVID-19 still has some way to go, selected nutraceuticals could be helpful, in addition to pharmacological therapy, in preventing some COVID-19-related complications in infected patients.

Keywords: SARS-CoV-2, COVID-19, infectious diseases, nutraceuticals, inflammation

\section{INTRODUCTION}

Several months ago, Chinese authorities identified an atypical pneumonia in Wuhan city, province of Hubei (China) and they reported it to the China Country Office of the World Health Organization (WHO) on $31^{\text {st }}$ December 2019. On $7^{\text {th }}$ January 2020, Chinese authorities isolated the aetiological agent as a novel coronavirus (2019-nCoV). The genetic sequence of $2019-\mathrm{nCoV}$ was shared with other countries to develop specific diagnostic kits on $12^{\text {th }}$ January 2020. In the following days, the Thai Ministry of Public Health, the Japanese Ministry of Health, Labour and Welfare, and the Korean Ministry of Health, Labour and Welfare reported their first imported case of laboratoryconfirmed $2019-\mathrm{nCoV}$ on $13^{\text {th }}$ January, $15^{\text {th }}$ January, and $20^{\text {th }}$ January 2020 , respectively. The International Committee on Taxonomy of Viruses classified the agent as SARS-CoV-2, given its similarity with the symptoms induced by SARS-CoV-1.

On $22^{\text {nd }}$ January 2020 the virus appeared in Europe, in Bavaria (Germany) from a German patient infected by an individual from Shanghai (China); on $25^{\text {th }}$ January 2020 , the virus was identified in Italy, in the area of Basso Lodigiano.

On $30^{\text {th }}$ January 2020 , the WHO declared the situation a public health emergency (1) and on $11^{\text {th }}$ February 2020, the WHO announced that the new disease was to be known as "COVID-19", an acronym of "COronaVIrus Disease-2019". 
On $20^{\text {th }}$ February 2020, Italian Authorities identified the first symptomatic COVID-19 patient at the Emergency Department of Codogno Hospital, Basso Lodigiano, province of Lodi.

On $26^{\text {th }}$ February 2020, the Director-General of the WHO announced that the number of new cases of COVID-19 reported outside China had exceeded the number of new cases in China (2). On $11^{\text {th }}$ March 2020, the WHO declared this viral disease as pandemic. Cases subsequently increased exponentially, reaching a total of 4.044 .762 , with 121.177 deaths, in Italy on $9^{\text {th }}$ May 2021. As of $11^{\text {th }}$ May 2021, the WHO has reported 158.551 .526 cases and 3.296.855 deaths that have occurred worldwide (3).

\section{AETIOLOGY}

Coronaviruses (CoVs) include a large group of single-stranded RNA viruses, with a crown-like appearance under an electron microscope.

CoVs were identified in the mid-1960s and they can infect humans and some animals (including birds and mammals). Their primary targets are the epithelial cells of the respiratory and gastrointestinal tracts.

The subfamily Orthocoronavirinae of the Coronaviridae family is classified into four $\mathrm{CoV}$ genera: alpha-CoV, beta$\mathrm{CoV}$, delta-CoV, and gamma-CoV. The beta-CoV genus is further divided into five subgenera (including Sarbecovirus) (4).

To date, seven CoVs are capable of infecting humans: 1) common human CoVs: HCoV-OC43 and HCoV-HKU1 (beta$\mathrm{CoV}$ ), and $\mathrm{HCoV}-229 \mathrm{E}$ and $\mathrm{HCoV}-\mathrm{NL} 63$ (alpha-CoV) - they are responsible of common colds, but also of serious lower respiratory tract infections; and 2) other human CoVs (betaCoV): SARS-CoV-1, MERS-CoV, and SARS-CoV-2 (5).

SARS-CoV-2 is a single-stranded, positive-sense RNA virus, with a diameter of 60-140 $\mathrm{nm}$ with a round or elliptic shape. It shares $96 \%$ sequence identity with bat genome (bat-SLCoVZC45), suggesting a very recent host shift into humans $(4,5)$.

\section{TRANSMISSION}

CoVs are hosted in nature by bats and the many CoVs present in humans are thought to derive from those in bats, which represent a reservoir (6).

Studies on the genomic sequence of SARS-CoV-2 identified a similarity of 50,79 , and $96 \%$ to MERS, SARS, and bat SARSrelated $\mathrm{CoV}$, respectively (7).

Currently, the specific route of transmission from natural reservoirs is unknown, but some studies suggest that the pangolin, which has viruses with more than $99 \%$ of the genome identical to SARS-CoV-2, is a worthy candidate for transmission (8).

The new CoV, SARS-CoV-2 is a respiratory virus spreading through the breath droplets of infected individuals. SARS-CoV-2 spreads through: 1) saliva, coughing, and sneezing; 2) direct personal contact; and 3) hands, for example, by touching the mouth, nose, or eyes with contaminated (unwashed) hands. Similarly to SARS-CoV-1, SARS-CoV-2 uses the angiotensinconverting enzyme II (ACE2) receptor expressed by human cells as an entry receptor (9).

The virus can survive on different surfaces for days and remain viable in aerosols for hours (10). Asymptomatic patients can carry and spread the virus, a high viral load has been identified in pharyngeal samples from minimally symptomatic patients during the initial period of the disease. The highest transmission rates correlate with disease severity and they are particularly pronounced in hospital settings, just as for SARS and MERS. The incubation period is between 3 and 14 days, and the onset of symptoms has been reported up to 14 days after exposure (11), providing the basis for the recommended length of quarantine/self-isolation (12).

\section{CLINICAL PATTERNS}

The symptoms that patients with COVID-19 may exhibit are variable. In the period from November to December 2019 in Italy, many general practitioners visited patients with a symptomatology that resembled influenza and which was not a common cold.

The symptoms, however, were similar and therefore confusing, such as fever, cough, and myalgias. Sometimes, nausea and diarrhoea could precede fever and respiratory symptoms. The persistence of this symptomatology, atypical for being a complicated influenza, caused doctors to request chest X-rays, with images often indicating pneumonia. After the statements from the Chinese authorities, the picture became clearer. Generally, patients are characterised by three main symptoms: 1) fever, 2) dry cough, and 3) dyspnoea.

In some patients, the latter may not be present initially, as this symptom may be decisive for hospitalisation or home follow-up. We have since learned that if COVID-19 is suspected and hospitalisation of the patient is envisaged, the emergency room must be avoided and testing and management must be conducted in rapidly accessible areas with a low risk of exposure to mitigate spread and to avoid overwhelming the healthcare system.

A first test to verify that the patient has been infected is swab sampling from the oropharynx or nasopharynx.

We can classify the infection as symptomatic or asymptomatic. Prodromal signs of the infection include conjunctivitis (often the first sign) or gastrointestinal symptoms such as nausea, vomiting, abdominal pain, and diarrhoea.

Some patients have only abdominal pain, anorexia, and dyspnoea without fever. Anosmia and dysgeusia can be present (13).

Older age, male sex, and smoking worsen the prognosis such as the presence of associated pathologies including obesity, hypertension, diabetes mellitus, cardiovascular disease, chronic kidney disease, and respiratory diseases. The greater is the number of risk factors and associated pathologies, the higher is the risk of a poor prognosis (14). 
A mild symptomatology can resolve without particular medical treatment at home or it can progress towards bilateral interstitial pneumonia and respiratory failure, requiring hospitalisation. Thrombotic complications seem to emerge as an important issue in infected patients. Clinical parameters to check include the presence of leucocytosis, thrombocytopenia, an elevated prothrombin time and partial thromboplastin time, and elevated levels of fibrinogen and D-dimers (15).

Patients can rapidly progress towards acute respiratory distress syndrome (ARDS) with multiple organ dysfunction syndrome (MODS) and death (16).

\section{THERAPY}

COVID-19 therapy is only supportive and prevention is the only way to reduce transmission and limit its spreading. Despite social distancing, hygiene measures, and screening, the COVID-19 pandemic is spreading quickly all over the world, with the risk that health systems will be unable to withstand its impact. At first, treatment with lopinavir/ritonavir and chloroquine/ hydroxychloroquine were attempted (17). In addition, a large number of antibiotics have been used, including ceftriaxone with azithromycin or piperacillin/tazobactam and doxycycline, and azithromycin alone.

From mid-March 2020, lopinavir/ritonavir was replaced with remdesivir and tocilizumab, also heparin was suggested as a potential treatment. Regarding glucocorticoids and their beneficial effects in the early stages of the disease, data are not so clear (18).

The use of plasma with antibodies obtained from patients recovered from COVID-19 seems to have a good rationale, although data are still from a limited number of patients (19).

While the development of effective "old-new" and new drug therapies is proceeding, with little success, vaccines are now available. There are several vaccines available. The first mass vaccination programme started in early December 2020. World Health Organization issued an Emergency Use Listing (EULs) for the Pfizer COVID-19 vaccine (BNT162b2) on December $31^{\text {st }}$ 2020. On February $15^{\text {th }} 2021$, WHO issued EULs for two versions of the AstraZeneca/Oxford COVID-19 vaccine, manufactured by the Serum Institute of India and SKBio. On March $12^{\text {th }}$ 2021, WHO issued an EUL for the COVID-19 vaccine Ad26.COV2.S, developed by Janssen (Johnson \& Johnson). WHO is on track to EUL other vaccine products through June. The most common side effect reported is soreness at the injection site. Less frequent side effects include fatigue, headache, muscle aches, chills, joint pain, and possibly some fever.

On this basis, this review will describe how the use of selected nutraceuticals could be helpful, in addition to pharmacological therapy, in preventing some COVID-19-related complications in infected patients.

References for this review were identified through searches within PubMed for articles published from January 2001 to May 2021 using the terms "Antiviral substances", "Nutraceuticals", and "COVID-19". Articles resulting from these searches and relevant references cited in those articles were reviewed. Only articles published in English were included.

\section{Nutraceuticals Possibly Helpful in Treating COVID-19-Infected Patients}

Since ancient time vegetables have been used by mankind as an important source of medicines. Currently, a wide portion of the world population still rely on botanical remedies to meet their health needs. Now we are witnessing an increasing interest and use of therapies with botanicals used to formulate healthcare products. Just to say, U.S. sales of herbals have increased by $8.5 \%$ from 2016 to 2017, recently reaching a likely estimated total of about 10 billion USD per year. Clearly, the increased public interest in botanicals has stimulated a greater scientific awareness aimed to better understand the pharmacological activity of medicinal plants. As it is well-known, many actives obtained from plant sources are indeed described to be endowed with pharmacological activities, and historically vegetables have yielded many important drugs for human use (i. e. morphine, vinblastine, vincristine, paclitaxel, and artemisinin). Although Big Pharma is not focusing on developing natural drugs from botanicals, natural products remain an important and viable source of lead compounds in many drug research programs. Finally, the development of natural products for the prevention and/or treatment of diseases continue to attract worldwide medical and financial attention (20).

As regards to the current coronavirus pandemic, several nutraceutical actives have indeed been described as being protective against some of those symptoms that are also considered manifestations of COVID-19 in infected patients. These include probiotics, polyphenols, high molecular weight polysaccharides, lectins, berberine, and others. Their use could therefore be possibly considered, if not in a curative context, then at least as a prophylactic, capable of reducing the burden and severity of the disease.

\section{Polyphenols}

From a pharmacological perspective, the most important targets with respect to SARS-CoV-2 include 3-chymotrypsin-like protease (3CLpro), papain-like protease (PLpro), RNAdependent RNA polymerase, and spike (S) protein (21). The S protein interacts directly with human ACE2, allowing the virus to enter cells. Naturally occurring antiviral agents acting against general CoVs were briefly reviewed six years ago (22), while more recent reviews by Pang et al. (23) and Lu (24) on therapies for COVID-19 made only short mention of natural therapeutics and did not explore the individual active compounds. In light of the current COVID-19 pandemic, some more precise information on extracts and/or individual compounds derived from natural products which show potential antiviral bioactivity for the inhibition of $\mathrm{CoV}$ can be given. Unarguably, the botanical family of compounds that demonstrates the greatest antiviral activity is the polyphenols. Quercetin showed an IC50 of $8.6 \pm$ 3.2 $\mu \mathrm{M}$ against SARS-CoV-1 PLpro (25). Quercetin is a common flavonoid found in many foods, berries, and herbs (and therefore, 
in extracts). Bearing in mind its very poor pharmacokinetic profile in animals and in humans, a bioavailable form of quercetin could be considered a better option to test (26). The structurally similar polyphenolics myricetin (Opuntia ficusindica) and scutellarein (Scutellaria baicalensis) display reasonable levels of inhibitory activity against SARS-CoV-1 helicase (27). Testing of a multi-fractionated ethanolic extract obtained from Psoralea corylifolia seeds has also identified polyphenols mediating activity versus SARS-CoV-1 PLpro (28). Furthermore, six phenolic phytochemicals were isolated from other ethanolic extracts and identified as bavachinin, neobavaisoflavone, isobavachalcone, 4'-O-methylbavachalcone, psoralidin, and corylifol A; all showed antiviral activity that varied widely, with IC50 values between 4.2 and $38.4 \mu \mathrm{M}$ (28).

\section{Lectins}

Botanical lectins, proteins binding specifically and reversibly to carbohydrate groups (29), may inhibit SARS-CoV-2. They showed some effects as antiviral agents against viruses such as influenza and herpes simplex (30), as well as Ebola (31). Of note, high plasma levels of recombinant human mannose-binding lectin in mice allowed them to survive otherwise fatal Ebola infections (32). Screening the activity of a broad range of 33 plant lectins against SARS-CoV-1 using a cytopathic effect inhibition assay, EC50 values as low as $0.45 \pm 0.08 \mu \mathrm{g} / \mathrm{mL}$ for Lycoris radiata agglutinin were found (33). A direct action at the stage of viral attachment or the end of the infectious viral cycle was believed to be the most likely underlying mechanism. Clinically, other lectins are well tolerated (34). Thus, lectins could be one of the more promising classes of naturally derived compounds for the treatment of SARS-CoV-2 infections.

\section{High Molecular Weight Polysaccharides}

In recent years, several natural products, mainly from herbal and mushroom extracts; for instance, Echinacea spp., ginseng, Astragalus (35), or shiitake derivatives (36), have been investigated for their immunomodulatory role against infective, including respiratory, diseases. Their use is generally considered a form of complementary and/or traditional medicine. For these natural extracts, the active compounds are thought to be high molecular weight polysaccharides, which have beneficial effects on health and disease probably due to a direct role in immunity (37). Regarding fungal derivatives, some mushroom extracts are used worldwide, mainly as dietary supplements and functional foods, to treat pathologies associated with immune dysregulation, including respiratory infections (38). The effects of selected mushroom derivatives on the immune system are likely due to the presence of $\beta$-glucans, which are thought to be capable of affecting innate and adaptive immune responses (39). In addition, other studies have reported the activation of NK and/or $\mathrm{T}$ cells by a different type of high molecular weight polysaccharides, named $\alpha$-glucans, effective in human and animal immunity, therefore suggesting a theoretical role in defending the host against respiratory infections (40). The most investigated and well-documented $\alpha$-glucan formulation, active hexose correlated compound (AHCC), has been shown to be effective against different types of infectious diseases caused by viruses such as West Nile virus, influenza virus, avian influenza virus, hepatitis $C$ virus, and human papillomavirus (41-47). In those studies, it was shown that NK cells, natural killer T (NKT) cells, and gamma delta $\mathrm{T}(\gamma \delta \mathrm{T})$ cells are modulated and activated by AHCC intake. NK, NKT, and $\gamma \delta \mathrm{T}$ cells represent primary interferon-gamma (IFN- $\gamma$ ) producers (48-50). As is well known, low pathogenic human $\mathrm{CoV}$ infects the upper airways and causes seasonal mild to moderate cold-like respiratory illnesses in healthy individuals. In contrast, the highly pathogenic viruses infect the lower respiratory tract and cause severe pneumonia, which sometimes leads to fatal acute lung injury (ALI) and ARDS, resulting in high morbidity and mortality (51). From this perspective, the host IFN- $\gamma$ response is, among others, one of the factors considered likely to be protective in preventing ALI and ARDS in subjects infected with highly pathogenic CoV (52). Although AHCC has never been tested against human CoVs, its mechanism of action makes it one of the best possible candidates to promote immunity in those subjects not yet infected but at considerable risk, or in those recently infected by SARS-CoV-2 (53). The most thoroughly investigated herbal derivatives in terms of their immunological properties are probably extracts from Echinacea angustifolia, Echinacea pallida, and Echinacea purpurea (54). Many human trials and meta-analyses have described their role in immunity and their capability to protect the host from URTI (55). The most highly purified and chemically characterised Echinacea extract is probably Polinacea ${ }^{\circledR}$. This has been described as promoting an interferon-mediated, T-cell response against viruses both in animals and in humans, with its mechanism of action also consisting of non-concomitant production of a proinflammatory cytokine cascade supported by IL-6 and/or TNF- $\alpha$ release $(56-59)$. This unique feature makes the extract a good candidate for COVID-19 prevention and possibly treatment.

\section{Natto}

Natto is a cheese-like food composed of soybeans fermented with Bacillus subtilis. It is a traditional food in Asian countries for more than 2,000 years and it plays a role in long life within the Japanese population. Several studies reported that high levels of natto consumption reduce the risk of total cardiovascular disease mortality and, in particular, reduce risk of mortality from ischaemic heart diseases (60) Relatively little was known regarding the mechanism by which natto intake led to an overall improvement in cardiovascular health until the 1980s. A potent fibrinolytic enzyme called nattokinase was discovered in natto in 1987 (61), and since then, nattokinase has been the subject of a considerable amount of research conducted in both Asian countries (Japan, China, Korea) and the United States. These studies have established that this enzyme, a 275-amino acid alkaline protease with a molecular weight of approximately $28 \mathrm{kDa}$, comprises the most active ingredient of natto, mediating its positive effects on cardiovascular health. Not only does nattokinase possess potent fibrinolytic/antithrombotic activity (62-64), but nattokinase has also been shown to exert antihypertensive, anti-atherosclerotic, lipid-lowering, antiplatelet/anticoagulant, and neuroprotective effects in 
both animal and human studies (65-72). All of these pharmacologic actions of nattokinase are relevant to the prevention and treatment of COVID-19. For example, supplementation with nattokinase enhanced markers of fibrinolysis and anticoagulation in human subjects, along with decreasing blood pressure and atherosclerosis (73-75). The most unique characteristic of nattokinase is that it has multiple cardiovascular disease-related preventative and alleviating pharmacologic effects (as mentioned, it has antithrombotic, antihypertensive, anticoagulant, anti-atherosclerotic, and neuroprotective effects): to the best of our knowledge, there are no other drugs with a similar range of pharmacologic properties. In addition, nattokinase is a natural product considered to be a "nutraceutical" in many countries throughout the world; it can be administered orally; it has a proven safety profile; it is inexpensive to use; and it provides many advantages in comparison to other pharmaceutical products. It therefore has the potential to be developed as a new-generation drug for the prevention, treatment, and long-term care of cardiovascular disease and, perhaps, COVID-19.

\section{Berberine}

Berberine, a quaternary ammonium salt from the protoberberine group of isoquinoline alkaloids, is mainly noted for its antilipogenic and hypoglycaemic effects (76-81). There is also evidence that berberine hydrochloride has antibacterial, antifungal, antiprotozoal, antihelminthic, and antiviral properties (82). Focusing on the antiviral activity of berberine, several studies assessed its antiviral effects against specific viruses such as influenza, cytomegalovirus (CMV), and herpes simplex. In in vivo studies, berberine administered to mice with influenza decreased mortality from $90 \%$ to $55 \%$, reducing virus titres in the lungs on day 2 post-infection. The production of nitric oxide (NO) and inducible nitric oxide synthase (iNOS) was repressed, along with inhibition of the transcription and expression of TNF- $\alpha$ and monocyte chemoattractant protein-1 (MCP-1). The possible mechanism underlying the therapeutic effects of berberine on influenza-induced viral pneumonia may be the inhibition of viral infection, as well as the improvement of pathogenic changes by repressing inflammatory substance release (83). Regarding its action in herpes simplex virus infection, berberine may interfere with the viral replication cycle after viral penetration and no later than the viral DNA synthesis step (84). Berberine also seems to have anti-human CMV (HCMV) activity, interfering with intracellular events after viral penetration into the host cells and before viral DNA synthesis (85).

\section{Botanicals Endowed With Anti- Inflammatory Properties}

One of the characteristics more thoroughly described for nutraceuticals, especially those derived from herbs, is that of being anti-inflammatory. Due to the large number of these derivatives, their complete and exhaustive description would go far beyond the remit of this review. However, if we limit our investigation to those extracted derivatives that have been extensively documented, including those used clinically and those for whom molecular details of the active ingredients contained within are precisely known, the list is considerably reduced in number. Among those of particular interest, as they are likely to have an anti-inflammatory role in the second phase of SARS-CoV-2 infection, the phase represented by the wellknown cytokine cascade which very often determines whether the patient will survive, we can list the derivatives from Curcuma longa, Boswellia serrata, and Nigella sativa. Curcuminoids, curcumin, and curcumin-like substances are polyphenolic structures that do not demonstrate direct antiviral activity (and thus, they have not been listed in the earlier subsection dedicated to polyphenols, 3.2) but they have been described in terms of their antagonistic capacity towards IL-6, IL-1, and TNF- $\alpha$ (86). As for quercetin, curcuminoids also appear to be characterised by a low oral bioavailability. For this reason, their co-administration with adjuvants such as piperine or the formation of complexes with phospholipids may be valuable $(87,88)$. The highly standardised extract containing boswellic acids and obtained from the resin of Boswellia serrata has also been widely described for its unique antagonistic action against the inflammatory cytokine (IL-6, TNF- $\alpha$ ) cascade (89). Even boswellic acids, unless used for their intestinal antiinflammatory properties, are more clinically active if complexed with phospholipids as they too are characterised by a suboptimal, if not poor, pharmacokinetic profile in animals and humans (90). Finally, we come to Nigella sativa. This is defined by the presence of thymoquinone, an active ingredient known for its lipid-lowering, antidiabetic (91), and, above all, antiinflammatory actions (92-94). Being a herbal derivative in an oily form, there are no major limitations in terms of pharmacokinetics associated with thymoquinone and it could therefore be an excellent and easily administered nutraceutical candidate capable of counteracting the cytokine storm that characterizes SARS-CoV-2 infection.

\section{Lactoferrin}

Lactoferrin is a highly conserved, iron-binding $80-\mathrm{kDa}$ glycoprotein that is expressed and secreted by glandular cells and is found in most body fluids including bovine and human milk. Lactoferrin seems to be able to moderate the host response to infections both stimulating the immune system to counteract germ invasion and preventing harmful host immune and inflammatory responses (95).

Starting from the eighties the list of lactoferrin-susceptible, both naked and enveloped as well as DNA and RNA, human viruses has grown and to date includes cytomegalovirus, herpes simplex virus, human immunodeficiency virus (HIV), rotavirus, poliovirus, respiratory syncytial virus, hepatitis $\mathrm{B}$ virus, hepatitis $\mathrm{C}$ virus (HCV), parainfluenza virus, alphavirus, hantavirus, human papillomavirus, adenovirus, enterovirus 71 , echovirus 6 , influenza A virus and Japanese encephalitis virus $(96,97)$.

Particularly relevant is the lactoferrin ability to inhibit pseudo-typed SARS-CoV (the human coronavirus that is most closely related to SARS-CoV-2, which causes COVID-19) with a $50 \%$ inhibitory concentration of $0.7 \mu \mathrm{M}$ (98). 
Human oral supplementation (100-1000 mg/day) of lactoferrin against pathologic viruses was found to reduce the incidence of colds and cold-like symptoms as well as to ameliorate rotaviral gastroenteritis (95). Moreover, a randomised controlled study involving $111 \mathrm{HCV}$ patients reported a significant decrease in $\mathrm{HCV}$ viral titres and sustained virological response in the lactoferrin group (99).

Besides to possibly show antiviral effects, lactoferrin has immunomodulatory and anti-inflammatory actions. Lactoferrin has the unique potential to maintain immune and physiological homeostasis and to limit tissue damage by modulation of cytokines, chemokines and cell surface receptors involved in cascades of signalling pathways (99).

With regards to the possible anti-inflammatory role played by lactoferrin, its use reduced many biological reactions normally seen upon experimentally lipopolysaccharide administration in a dose-dependent manner, and in an earlier study a single dose of lactoferrin prior to lipopolysaccharide injection reduced the mortality of mice to $16.7 \%$ compared with $83.3 \%$ in controls (100).

Due to the promising results got in experimental studies, lactoferrin has been investigated in some clinical studies against sepsis and recently, a meta-analysis of well-performed randomised controlled trials involving about 4000 infant showed that lactoferrin reduces late-onset sepsis (101).

To date, no clinical data have been produced to confirm a possible anti-COVID-19 effect of lactoferrin. Anyway, lactoferrin strongly affects immune response and cellular inflammation. Therefore, this natural component could provide a promising effect in preventing respiratory infections and potentially also for COVID-19. If the assumption that lactoferrin could modulate an overactive immune and inflammatory response to viral infection is correct, lactoferrin could be a candidate adjunct treatment for severe cases of COVID-19 (102).

\section{Vitamins, Minerals, and Omega-3 Fatty Acids}

Since COVID-19 dysregulates the immune system, it seems important to evaluate the role played on immunity by simple nutritional elements like vitamins, minerals, and fomega-3 fatty acids.

Vitamin D has a well-known impact on immunity. It enhances innate cellular immunity through stimulation of expression of anti-microbial peptides which also maintain tight and gap junctions and enhance the expression of anti-oxidative genes. Vitamin D also promotes the differentiation of monocytes to macrophages, whilst increasing superoxide production, phagocytosis and bacterial destruction. Moreover, vitamin D modulates the adaptive immune response, it suppresses $\mathrm{T}$ helper type-1 (Th1) cell function and decreases the production of pro-inflammatory cytokines IL-2 and interferon-gamma (INF- $\gamma$ ). Vitamin D also promotes anti-inflammatory cytokines by Th2 cells and indirectly suppressing Th1 cells diverting proinflammatory cells to an anti-inflammatory phenotype as well as stimulating suppressive regulatory $\mathrm{T}$ cells (103). Low plasma levels of vitamin D seem to increase incidence and severity of COVID-19 infection. COVID-19 patients had lower levels of vitamin $\mathrm{D}$, with mean plasma concentrations half that of controls (104). This could suggest for vitamin D a role in boosting immunity against COVID-19 and in reducing human mortality. Of course, this hypothesis needs to be tested in severely controlled human trials.

Vitamin C seems to have protective actions in infectious disease. Vitamin C supplementation supports respiratory defence mechanisms, prevents viral infections, and reduces their duration and severity. Vitamin $\mathrm{C}$ also has anti-histamine properties that can improve flu-like symptoms. A number of important reviews have been devoted to clarify a possible antiCOVID-19 vitamin C role and our review could not go deeper being not dedicated exclusively to it (105). On the basis of the many data available, vitamin $\mathrm{C}$ supplementation could be surely considered a sensible option in micronutrient deficient individuals that are at risk of COVID-19 infection to assist with the prevention and support of immune responses. To this end, several clinical trials are evaluating Vitamin $\mathrm{C}$ supplementation in COVID-19 patients.

Zinc has immunomodulatory and anti-viral properties (106) which could be helpful in treating COVID-19 patients (107). Zinc supplementation can decrease COVID-19 related symptoms such as lower respiratory tract infection. These effects are likely due to inhibition of viral uncoating, binding and replication, and therefore may be relevant to COVID-19. Due to that, a clinical trial registered in Australia will be soon able to determine if the use of intravenous zinc administration in COVID-19 positive individuals could modify the course of the infection (108).

Eicosapentaenoic and docosahexaenoic fatty acids are polyunsaturated fatty acids (omega-3) with favourable effects on immunity and inflammation. Omega-3 fatty acids seems also to exert an anti-viral effects in case of influenza virus. Noteworthy, the use of omega-3 fatty acids improved oxygenation in COVID-19 patients, although real evidence is still missing (109). In our opinion anyway, the use of the omega3 in COVID-19 patients should be done with caution, due to a counter-intuitive increase in oxidative stress and inflammation due to increased susceptibility of cellular membranes to damage (110). Therefore, until there are validated trial data, omega-3 supplementation, particularly in high doses, must be performed with care in this population.

Vitamin E, vitamin A, magnesium, and trace element selenium, have been also cited by researchers as possible tools to be used to counteract the impact of coronavirus on immunity, especially as regards to vulnerable subjects, including elderly and immunocompromised (111). Anyway, the findings available are scares and further evidence are required.

\section{Nutraceuticals for COVID-19?}

There are limited proven therapeutic options for the prevention and treatment of COVID-19. The role of nutraceuticals, botanicals, vitamin and mineral approach "to feed immunity" 
has been explored by many researchers all over the world and currently there are several hypotheses to support their routine use. The aim of this narrative review was to investigate if nutraceutical supplementation could be beneficial in COVID19. Although there are currently no published controlled clinical trials, also due to the novelty of SARS-CoV-2 infection, there is strong pathophysiologic rationale for exploring the use of nutraceuticals in this global pandemic, supported by many reports from international groups. On the other side, we cannot claim a role for nutraceutical that remains to be demonstrated, underlining the need not to make promises that would risk to be disappointed by future results.

\section{REFERENCES}

1. World Health Organization. Available at: https://www.who.int/news-room/ detail/30-01-2020-statement-on-the-second-meeting-of-the-internationalhealth-regulations-(2005)-emergency-committee-regarding-the-outbreakof-novel-coronavirus-(2019-ncov) (Accessed July 8th 2020).

2. World Health Organization. Available at: https://www.who.int/dg/speeches/ detail/who-director-general-s-opening-remarks-at-the-mission-briefingon-covid-19-26-february-2020 (Accessed July 8th 2020).

3. World Health Organization. Available at: https://www.who.int/ emergencies/diseases/novel-coronavirus-2019 (Accessed July 8th 2020).

4. Chan JF, To KK, Tse H, Jin DJ, Yuen KY. Interspecies Transmission and Emergence of Novel Viruses: Lessons From Bats and Birds. Trends Microbiol (2013) 21:544-55. doi: 10.1016/j.tim.2013.05.005

5. Chen Y, Liu Q, Guo D. Emerging Coronaviruses: Genome Structure, Replication, and Pathogenesis. J Med Virol (2020) 92:418-23. doi: 10.1002/jmv.25681

6. Zhou P, Yang XL, Wang XG, Hu B, Zhang L, Zhang W, et al. A Pneumonia Outbreak Associated With a New Coronavirus of Probable Bat Origin. Nature (2020) 579:270-3. doi: 10.1038/s41586-020-2012-7

7. Li W, Shi Z, Yu M, Ren W, Smith C, Epstein JH, et al. Bats are Natural Reservoirs of SARS-like Coronaviruses. Science (2005) 310:676-9. doi: $10.1126 /$ science. 1118391

8. Tang X, Wu C, Li X, Song Y, Yao X, Wu X, et al. On the Origin and Continuing Evolution of SARS-CoV-2. Natl Sci Rev (2020) 7(6):1012-23. doi: 10.1093/nsr/nwaa036

9. Li Q, Guan X, Wu P, Wang X, Zhou L, Tong Y, et al. Early Transmission Dynamics in Wuhan, China, of Novel Coronavirus-Infected Pneumonia. N Engl J Med (2020) 382:1199-207. doi: 10.1056/NEJMoa2001316

10. van Doremalen N, Bushmaker T, Morris DH, Holbrook MG, Gamble A, Williamson BN, et al. Aerosol and Surface Stability of SARS-CoV-2 as Compared With SARS-CoV-1. N Engl J Med (2020) 382:1564-7. doi: 10.1056/NEJMc2004973

11. Lauer SA, Grantz KH, Bi Q, Jones FK, Zheng Q, Meredith HR, et al. The Incubation Period of Coronavirus Disease 2019 (COVID-19) From Publicly Reported Confirmed Cases: Estimation and Application. Ann Intern Med (2020) 172(9):577-82. doi: 10.7326/M20-0504

12. He X, Lau EHY, Wu P, Deng X, Wang J, Hao X, et al. Temporal Dynamics in Viral Shedding and Transmissibility of COVID-19. Nat Med (2020) 26 (5):672-5. doi: 10.1038/s41591-020-0869-5

13. Huang C, Wang Y, Li X, Ren L, Zhao J, Hu Y, et al. Clinical Features of Patients Infected With 2019 Novel Coronavirus in Wuhan, China. Lancet (2020) 395:497-506. doi: 10.1016/S0140-6736(20)30183-5

14. Chen N, Zhou M, Dong X, Qu J, Gong F, Han Y, et al. Epidemiological and Clinical Characteristics of 99 Cases of 2019 Novel Coronavirus Pneumonia in Wuhan, China: A Descriptive Study. Lancet (2020) 395:507-13. doi: 10.1016/S0140-6736(20)30211-7

15. Giannis D, Ziogas IA, Gianni P. Coagulation Disorders in Coronavirus Infected Patients: COVID-19, SARS-CoV-1, MERS-CoV and Lessons From the Past. J Clin Virol (2020) 127:104362. doi: 10.1016/j.jcv. 2020.104362

\section{CONCLUSIONS}

Even if a specific and effective cure for COVID-19 still has some way to go, selected nutraceuticals could be helpful, in addition to pharmacological therapy, in preventing some COVID-19-related complications in infected patients.

\section{AUTHOR CONTRIBUTIONS}

All authors were equally involved in writing this review. All authors contributed to the article and approved the submitted version.

16. Wang D, Hu B, Hu C, Zhu F, Liu X, Zhang J, et al. Clinical Characteristics of 138 Hospitalized Patients With 2019 Novel Coronavirus-Infected Pneumonia in Wuhan, China. JAMA (2020) 323:1061-9. doi: 10.1001/ jama.2020.1585

17. Dong L, Hu S, Gao J. Discovering Drugs to Treat Coronavirus Disease 2019 (COVID-19). Drug Discov Ther (2020) 14:58-60. doi: 10.5582/ ddt.2020.01012

18. Zhang W, Zhao Y, Zhang F, Wang Q, Li T, Liu Z, et al. The Use of AntiInflammatory Drugs in the Treatment of People With Severe Coronavirus Disease 2019 (COVID-19): The Perspectives of Clinical Immunologists From China. Clin Immunol (2020) 214:108393. doi: 10.1016/ j.clim.2020.108393

19. Zeng QL, Yu ZJ, Gou JJ, Li GM, Ma SH, Zhang GF, et al. Effect of Convalescent Plasma Therapy on Viral Shedding and Survival in COVID19 Patients. J Infect Dis (2020) 222(1):38-43. doi: 10.1093/infdis/jiaa228

20. Che CT, Zhang H. Plant Natural Products for Human Health. Int J Mol Sci (2019) 20(4):830. doi: 10.3390/ijms20040830

21. Wu C, Liu Y, Yang Y, Zhang P, Zhong W, Wang Y, et al. Analysis of Therapeutic Targets for SARS-CoV-2 and Discovery of Potential Drugs by Computational Methods. Acta Pharm Sin B (2020) 10(5):766-88. doi: 10.1016/j.apsb.2020.02.008

22. Lin LT, Hsu WC, Lin CC. Antiviral Natural Products and Herbal Medicines. J Tradit Complement Med (2014) 4(1):24-35. doi: 10.4103/22254110.124335

23. Pang J, Wang MX, Ang IYH, Tan SHX, Lewis RF, Chen JIP, et al. Potential Rapid Diagnostics, Vaccine and Therapeutics for 2019 Novel Coronavirus (2019-ncoV): A Systematic Review. J Clin Med (2020) 9(3):623. doi: 10.3390/ jcm9030623

24. Lu H. Drug Treatment Options for the 2019-New Coronavirus (2019nCoV). Biosci Trends (2020) 14(1):69-71. doi: 10.5582/bst.2020.01020

25. Park JY, Yuk HJ, Ryu HW, Lim SH, Kim KS, Park KH, et al. Evaluation of Polyphenols From Broussonetia Papyrifera as Coronavirus Protease Inhibitors. J Enzyme Inhib Med Chem (2017) 32(1):504-15. doi: 10.1080/ 14756366.2016.1265519

26. Riva A, Ronchi M, Petrangolini G, Bosisio S, Allegrini P. Improved Oral Absorption of Quercetin From Quercetin Phytosome ${ }^{\circledR}$, a New Delivery System Based on Food Grade Lecithin. Eur J Drug Metab Pharmacokinet (2019) 44(2):169-77. doi: 10.1007/s13318-018-0517-3

27. Yu MS, Lee J, Lee JM, Kim Y, Chin YW, Jee JG, et al. Identification of Myricetin and Scutellarein as Novel Chemical Inhibitors of the SARS Coronavirus Helicase, nsP13. Bioorg Med Chem Lett (2012) 22(12):404954. doi: 10.1016/j.bmcl.2012.04.081

28. Kim DW, Seo KH, Curtis-Long MJ, Oh KY, Oh JW, Cho JK, et al. Phenolic Phytochemical Displaying SARS-CoV Papain-Like Protease Inhibition From the Seeds of Psoralea Corylifolia. J Enzyme Inhib Med Chem (2014) 29(1):59-63. doi: 10.3109/14756366.2012.753591

29. Mitchell CA, Ramessar K, O'Keefe BR. Antiviral Lectins: Selective Inhibitors of Viral Entry. Antiviral Res (2017) 142:37-54. doi: 10.1016/ j.antiviral.2017.03.007

30. Hwang HJ, Han JW, Jeon H, Cho K, Kim JH, Lee DS, et al. Characterization of a Novel Mannose-Binding Lectin With Antiviral Activities From Red 
Alga, Grateloupia Chiangii. Biomolecules (2020) 10(2):333. doi: 10.3390/ biom10020333

31. Covés-Datson EM, Dyall J, DeWald LE, King SR, Dube D, Legendre M, et al. Inhibition of Ebola Virus by a Molecularly Engineered Banana Lectin. PloS Negl Trop Dis (2019) 13(7):e0007595. doi: 10.1371/journal.pntd.0007595

32. Michelow IC, Lear C, Scully C, Prugar LI, Longley CB, Yantosca LM, et al. High-Dose Mannose-Binding Lectin Therapy for Ebola Virus Infection. J Infect Dis (2011) 203(2):175-9. doi: 10.1093/infdis/jiq025

33. Keyaerts E, Vijgen L, Pannecouque C, Van Damme E, Peumans W, Egberink $\mathrm{H}$, et al. Plant Lectins are Potent Inhibitors of Coronaviruses by Interfering With Two Targets in the Viral Replication Cycle. Antiviral Res (2007) 75 (3):179-87. doi: 10.1016/j.antiviral.2007.03.003

34. Petersen KA, Matthiesen F, Agger T, Kongerslev L, Thiel S, Cornelissen K, et al. Phase I Safety, Tolerability, and Pharmacokinetic Study of Recombinant Human Mannan-Binding Lectin. J Clin Immunol (2006) 26 (5):465-75. doi: 10.1007/s10875-006-9037-z

35. Block KI, Mead MN. Immune System Effects of Echinacea, Ginseng, and Astragalus: A Review. Integr Cancer Ther (2003) 2(3):247-67. doi: 10.1177/ 1534735403256419

36. Wasser SP. Medicinal Mushrooms in Human Clinical Studies. Part I. Anticancer, Onco-Immunological, and Immunomodulatory Activities: A Review. Int J Med Mushrooms (2017) 19(4):279-317. doi: 10.1615/ IntJMedMushrooms.v19.i4.10

37. Fu J, Zhang S, Wu J, Chen Y, Zhong Y, Zhou Y, et al. Structural Characterization of a Polysaccharide From Dry Mycelium of Penicillium Chrysogenum That Induces Resistance to Tobacco Mosaic Virus in Tobacco Plants. Int J Biol Macromol (2020) 156:67-79. doi: 10.1016/ j.ijbiomac.2020.04.050

38. Jesenak M, Urbancikova I, Banovcin P. Respiratory Tract Infections and the Role of Biologically Active Polysaccharides in Their Management and Prevention. Nutrients (2017) 9(7):779. doi: 10.3390/nu9070779

39. Meng X, Liang H, Luo L. Antitumor Polysaccharides From Mushrooms: A Review on the Structural Characteristics, Antitumor Mechanisms and Immunomodulating Activities. Carbohydr Res (2016) 424:30-41. doi: 10.1016/j.carres.2016.02.008

40. Sato K, Kashimoto M. Profile Summary of AHCC: Composition. In: AD Kulkarni and T Calder PC. Ito, editors. Clinician's Guide to AHCC. International Congress on Nutrition and Integrative Medicine (2017). p. 24-33.

41. Shin MS, Park HJ, Maeda T, Nishioka H, Fujii H, Kang I. The Effects of AHCC $^{\circledR}$, a Standardized Extract of Cultured Lentinura Edodes Mycelia, on Natural Killer and T Cells in Health and Disease: Reviews on Human and Animal Studies. J Immunol Res (2019), 3758576. doi: 10.1155/2019/3758576

42. Wang S, Welte T, Fang H, Chang GJJ, Born WK, O'Brien RL, et al. Oral Administration of Active Hexose Correlated Compound Enhances Host Resistance to West Nile Encephalitis in Mice. J Nutr (2009) 139(3):598-602. doi: $10.3945 /$ jn. 108.100297

43. Roman BE, Beli E, Duriancik DM, Gardner EM. Short-Term Supplementation With Active Hexose Correlated Compound Improves the Antibody Response to Influenza B Vaccine. Nutr Res (2013) 33(1):127. doi: $10.1016 /$ j.nutres.2012.11.001

44. Nogusa S, Gerbino J, Ritz BW. Low-Dose Supplementation With Active Hexose Correlated Compound Improves the Immune Response to Acute Influenza Infection in C57BL/6 Mice. Nutr Res (2009) 29(2):139-43. doi: 10.1016/j.nutres.2009.01.005

45. Ritz BW, Nogusa S, Ackerman EA, Gardner EM. Supplementation With Active Hexose Correlated Compound Increases the Innate Immune Response of Young Mice to Primary Influenza Infection. J Nutr (2006) 136(11):2868-73. doi: 10.1093/jn/136.11.2868

46. Thaiudom S, Piyaniran W, Chutaputthi A. A Study of the Efficacy of Active Hexose Correlated Compound (AHCC) in the Treatment of Chronic Hepatitis C Patients at Phramongkutklao Hospital. Med News Thailand (2010) 325:13-6.

47. Smith JA, Mathew L, Gaikwad A, Rech B, Burney MN, Faro JP, et al. From Bench to Bedside: Evaluation of AHCC Supplementation to Modulate the Host Immunity to Clear High-Risk Human Papillomavirus Infections. Front Oncol (2019) 9:173. doi: 10.3389/fonc.2019.00173

48. Perussia B. The Cytokine Profile of Resting and Activated NK Cells. Methods (1996) 9(2):370-8. doi: 10.1006/meth.1996.0042
49. Ghazarian L, Simoni Y, Magalhaes I, Lehuen A. Invariant NKT Cell Development: Focus on NOD Mice. Curr Opin Immunol (2014) 27:83-8. doi: 10.1016/j.coi.2014.02.004

50. Muñoz-Ruiz M, Sumaria N, Pennington DJ, Silva-Santos B. Thymic Determinants of $\gamma \delta \mathrm{T}$ Cell Differentiation. Trends Immunol (2017) 38 (5):336-44. doi: 10.1016/j.it.2017.01.007

51. Kuiken T, Fouchier RAM, Schutten M, Rimmelzwaan GF, van Amerongen G, van Riel D, et al. Newly Discovered Coronavirus as the Primary Cause of Severe Acute Respiratory Syndrome. Lancet (2003) 362(9380):263-70. doi: 10.1016/S0140-6736(03)13967-0

52. Channappanavar R, Perlman S. Pathogenic Human Coronavirus Infections: Causes and Consequences of Cytokine Storm and Immunopathology. Semin Immunopathol (2017) 39(5):529-39. doi: 10.1007/s00281-017-0629-x

53. Di Pierro F, Bertuccioli A, Cavecchia I. Possible Therapeutic Role of a Highly Standardized Mixture of Active Compounds Derived From Cultured Lentinula Edodes Mycelia (AHCC) in Patients Infected With 2019 Novel Coronavirus. Minerva Gastroenterol Dietol (2020) 66(2):172-6. doi: 10.23736/S1121-421X.20.02697-5

54. Bruni R, Brighenti V, Caesar LK, Bertelli D, Cech NB, Pellati F. Analytical Methods for the Study of Bioactive Compounds From Medicinally Used Echinacea Species. J Pharm BioMed Anal (2018) 160:443-77. doi: 10.1016/ j.jpba.2018.07.044

55. David S, Cunningham R. Echinacea for the Prevention and Treatment of Upper Respiratory Tract Infections: A Systematic Review and MetaAnalysis. Complement Ther Med (2019) 44:18-26. doi: 10.1016/ j.ctim.2019.03.011

56. Morazzoni P, Cristoni A, Di Pierro F, Avanzini C, Ravarino D, Stornello S, et al. In Vitro and In Vivo Immune Stimulating Effects of a New Standardized Echinacea Angustifolia Root Extract (Polinacea). Fitoterapia (2005) 76(5):401-11. doi: 10.1016/j.fitote.2005.02.001

57. Di Pierro F, Rapacioli G, Ferrara T, Togni S. Use of a Standardized Extract From Echinacea Angustifolia (Polinacea) for the Prevention of Respiratory Tract Infections. Altern Med Rev (2012) 17(1):36-41.

58. Dapas B, Dall'Acqua S, Bulla R, Agostinis C, Perissutti B, Invernizzi S, et al. Immunomodulation Mediated by a Herbal Syrup Containing a Standardized Echinacea Root Extract: A Pilot Study in Healthy Human Subjects on Cytokine Gene Expression. Phytomedicine (2014) 21(11):1406-10. doi: 10.1016/j.phymed.2014.04.034

59. Gaspari V, D'Antuono A, Patrizi A. Efficacy and Tolerability of Supplementation With Polinacea ${ }^{\circledR}$ and $\mathrm{AM}^{\circledR}{ }^{\circledR}$ in the Clearance of AnoGenital Warts: A Single-Center Observational Study in Adults. G Ital Dermatol Venereol (2016) 151(4):460-2.

60. Nagata C, Wada K, Tamura T, Konishi K, Goto Y, Koda S, et al. Dietary Soy and Natto Intake and Cardiovascular Disease Mortality in Japanese Adults: The Takayama Study. Am J Clin Nutr (2017) 105:426-31. doi: 10.3945/ ajcn.116.137281

61. Sumi H, Hamada H, Tsushima H, Mihara H, Muraki H. A Novel Fibrinolytic Enzyme (Nattokinase) in the Vegetable Cheese Natto; a Typical and Popular Soybean Food in the Japanese Diet. Experientia (1987) 43:1110-1. doi: 10.1007/BF01956052

62. Urano T, Ihara H, Umemura K, Suzuki Y, Oike M, Akita S, et al. The Profibrinolytic Enzyme Subtilisin NAT Purified From Bacillus Subtilis Cleaves and Inactivates Plasminogen Activator Inhibitor Type 1. J Biol Chem (2001) 276:24690-6. doi: 10.1074/jbc.M101751200

63. Fujita M, Hong K, Ito Y, Fujii R, Kariya K, Nishimuro S. Thrombolytic Effect of Nattokinase on a Chemically Induced Thrombosis Model in Rat. Biol Pharm Bull (1995) 18:1387-91. doi: 10.1248/bpb.18.1387

64. Sumi H, Hamada H, Nakanishi K, Hiratani H. Enhancement of the Fibrinolytic Activity in Plasma by Oral Administration of Nattokinases. Acta Haematol (1990) 84:139-43. doi: 10.1159/000205051

65. Fujita M, Ohnishi K, Takaoka S, Ogasawara K, Fukuyama R, Nakamuta H. Antihypertensive Effects of Continuous Oral Administration of Nattokinase and its Fragments in Spontaneously Hypertensive Rats. Biol Pharm Bull (2011) 34:1696-701. doi: 10.1248/bpb.34.1696

66. Kim JY, Gum SN, Paik JK, Lim HH, Kim KC, Ogasawara K, et al. Effects of Nattokinase on Blood Pressure: A Randomized, Controlled Trial. Hypertens Res (2008) 31:1583-8. doi: 10.1291/hypres.31.1583 
67. Ren N, Chen H, Li Y, McGowan E, Lin Y. A Clinical Study on the Effect of Nattokinase on Carotid Artery Atherosclerosis and Hyperlipidaemia. Nat Med J China (2017) 97:2038-42.

68. Suzuki Y, Kondo K, Matsumoto Y, Zhao BQ, Otsuguro K, Maeda T, et al. Dietary Supplementation of Fermented Soybean, Natto, Suppresses Intimal Thickening and Modulates the Lysis of Mural Thrombi After Endothelial Injury in Rat Femoral Artery. Life Sci (2003) 73:1289-98. doi: 10.1016/ S0024-3205(03)00426-0

69. Duan Z, Jiang X, Jiang H, Zhang S, Dong M, Zhao X. Study on the Antioxidative Activity and Effects on Experimental Hyperlipidemia of Natto Extract. Acta Nutrimenta Sin (2003) 26:296-9.

70. Jang JY, Kim TS, Cai J, Kim J, Kim Y, Shin K, et al. Nattokinase Improves Blood Flow by Inhibiting Platelet Aggregation and Thrombus Formation. Lab Anim Res (2013) 29:221-5. doi: 10.5625/lar.2013.29.4.221

71. Fadl N, Ahmed H, Booles H, Sayed A. Serrapeptase and Nattokinase Intervention for Relieving Alzheimer's Disease Pathophysiology in Rat Model. Hum Exp Toxicol (2013) 32:721-35. doi: 10.1177/0960327112467040

72. Ji H, Yu L, Liu K, Yu Z, Zhang Q, Zou F, et al. Mechanisms of Nattokinase in Protection of Cerebral Ischemia. Eur J Pharmacol (2014) 745:144-51. doi: 10.1016/j.ejphar.2014.10.024

73. Jensen GS, Lenninger M, Ero MP, Benson KF. Consumption of Nattokinase is Associated With Reduced Blood Pressure and Von Willebrand Factor, a Cardiovascular Risk Marker: Results From a Randomized, Double-Blind, Placebo-Controlled, Multicenter North American Clinical Trial. Integr Blood Press Control (2016) 9:95-104. doi: 10.2147/IBPC.S99553

74. Kurosawa Y, Nirengi S, Homma T, Esaki K, Ohta M, Clark JF, et al. A SingleDose of Oral Nattokinase Potentiates Thrombolysis and Anti-Coagulation Profiles. Sci Rep (2015) 5:11601. doi: 10.1038/srep11601

75. Hsia CH, Shen MC, Lin JS, Wen YK, Hwang KL, Cham TM, et al. Nattokinase Decreases Plasma Levels of Fibrinogen, Factor VII, and Factor VIII in Human Subjects. Nutr Res (2009) 29:190-6. doi: 10.1016/ j.nutres.2009.01.009

76. Derosa G, Maffioli P. Alkaloids in the Nature: Pharmacological Applications in Clinical Practice of Berberine and Mate Tea. Curr Top Med Chem (2014) 14(2):200-6. doi: 10.2174/1568026613666131213155252

77. Derosa G, Maffioli P, Cicero AF. Berberine on Metabolic and Cardiovascular Risk Factors: An Analysis From Preclinical Evidences to Clinical Trials. Expert Opin Biol Ther (2012) 12(8):1113-24. doi: 10.1517/ 14712598.2012.704014

78. Derosa G, D’Angelo A, Bonaventura A, Bianchi L, Romano D, Maffioli P. Effects of Berberine on Lipid Profile in Subjects With Low Cardiovascular Risk. Expert Opin Biol Ther (2013) 13(4):475-82. doi: 10.1517/ 14712598.2013.776037

79. Derosa G, D’Angelo A, Romano D, Maffioli P. Effects of a Combination of Berberis Aristata, Silybum Marianum and Monacolin on Lipid Profile in Subjects at Low Cardiovascular Risk; a Double-Blind, Randomized, PlaceboControlled Trial. Int J Mol Sci (2017) 18(2). doi: 10.3390/ijms18020343

80. Derosa G, Romano D, D’Angelo A, Maffioli P. Berberis Aristata/Silybum Marianum Fixed Combination (Berberol $\left({ }^{\circledR}\right)$ ) Effects on Lipid Profile in Dyslipidemic Patients Intolerant to Statins at High Dosages: A Randomized, Placebo-Controlled, Clinical Trial. Phytomedicine (2015) 22 (2):231-7. doi: 10.1016/j.phymed.2014.11.018

81. Derosa G, Romano D, D’Angelo A, Maffioli P. Berberis Aristata Combined With Silybum Marianum on Lipid Profile in Patients Not Tolerating Statins at High Doses. Atherosclerosis (2015) 239(1):87-92. doi: 10.1016/ j.atherosclerosis.2014.12.043

82. Patil T, Patil S, Patil S, Patil A. Antimicrobial Profile of Antidiabetic Drug: Berberine. IJPPR (2015) 7(1):45-50. doi: 10.1186/s12906-019-2558-9

83. Wu Y, Li JQ, Kim YJ, Wu J, Wang Q, Hao Y. In Vivo and In Vitro Antiviral Effects of Berberine on Influenza Virus. Chin J Integr Med (2011) 17:444-52. doi: 10.1007/s11655-011-0640-3

84. Chin LW, Cheng YW, Lin SS, Lai YY, Lin LY, Chou MY, et al. Anti-Herpes Simplex Virus Effects of Berberine From Coptidis Rhizoma, a Major Component of a Chinese Herbal Medicine. Arch Virol (2010) 155:193341. doi: 10.1007/s00705-010-0779-9

85. Hayashi K, Minoda K, Nagaoka Y, Hayashi T, Uesato S. Antiviral Activity of Berberine and Related Compounds Against Human Cytomegalovirus. Bioorg Med Chem Lett (2007) 17:1562-4. doi: 10.1016/j.bmcl.2006.12.085
86. Huang K, Shi C, Min J, Li L, Zhu T, Yu H, et al. Study on the Mechanism of Curcumin Regulating Lung Injury Induced by Outdoor Fine Particulate Matter (PM2.5). Mediators Inflamm (2019), 8613523. doi: 10.1155/2019/ 8613523

87. Kazi M, Shahba AA, Alrashoud S, Alwadei M, Sherif AY, Alanazi FK. Bioactive Self-Nanoemulsifying Drug Delivery Systems (Bio-SNEDDS) for Combined Oral Delivery of Curcumin and Piperine. Molecules (2020) 25 (7):1703. doi: 10.3390/molecules25071703

88. Teng CF, Yu CH, Chang HY, Hsieh WC, Wu TH, Lin JH, et al. Chemopreventive Effect of Phytosomal Curcumin on Hepatitis B VirusRelated Hepatocellular Carcinoma in A Transgenic Mouse Model. Sci Rep (2019) 9(1):10338. doi: 10.1038/s41598-019-46891-5

89. Roy NK, Parama D, Banik K, Bordoloi D, Devi AK, Thakur KK, et al. An Update on Pharmacological Potential of Boswellic Acids Against Chronic Diseases. Int J Mol Sci (2019) 20(17):4101. doi: 10.3390/ijms20174101

90. Di Pierro F, Simonetti G, Petruzzi A, Bertuccioli A, Botta L, Bruzzone MG, et al. A Novel Lecithin-Based Delivery Form of Boswellic Acids as Complementary Treatment of Radiochemotherapy-Induced Cerebral Edema in Patients With Glioblastoma Multiforme: A Longitudinal Pilot Experience. J Neurosurg Sci (2019) 63(3):286-91. doi: 10.23736/S03905616.19.04662-9

91. Najmi A, Nasiruddin M, Khan RA, Haque SF. Effect of Nigella Sativa Oil on Various Clinical and Biochemical Parameters of Insulin Resistance Syndrome. Int J Diabetes Dev Ctries (2008) 28(1):11-4. doi: 10.4103/09733930.41980

92. Rashidmayvan M, Mohammadshahi M, Seyedian SS, Haghighizadeh MH. The Effect of Nigella Sativa Oil on Serum Levels of Inflammatory Markers, Liver Enzymes, Lipid Profile, Insulin and Fasting Blood Sugar in Patients With Non-Alcoholic Fatty Liver. J Diabetes Metab Disord (2019) 18(2):4539. doi: 10.1007/s40200-019-00439-6

93. Isik F, Akbay TT, Yarat A, Genc Z, Pisiriciler R, Caliskan-Ak E, et al. Protective Effects of Black Cumin (Nigella Sativa) Oil on TNBS-Induced Experimental Colitis in Rats. Dig Dis Sci (2011) 56(3):721-30. doi: 10.1007/ s10620-010-1333-z

94. Elsherbiny NM, El-Sherbiny M. Thymoquinone Attenuates DoxorubicinInduced Nephrotoxicity in Rats: Role of Nrf2 and NOX4. Chem Biol Interact (2014) 223:102-8. doi: 10.1016/j.cbi.2014.09.015

95. Chang R, Ng TB, Sun WZ. Lactoferrin as Potential Preventative and Adjunct Treatment for COVID-19. Int J Antimicrob Agents (2020) 56(3):106118. doi: 10.1016/j.ijantimicag.2020.106118

96. Ng TB, Cheung RCF, Wong JH, Wang Y, Ip DTM, Wan DCC. Antiviral Activities of Whey Proteins. Appl Microbiol Biotechnol (2015) 99:6997-7008. doi: 10.1007/s00253-015-6818-4

97. Wakabayashi H, Oda H, Yamauchi K, Abe F. Lactoferrin for Prevention of Common Viral Infections. J Infect Chemother (2014) 20:666-71. doi: 10.1016/j.jiac.2014.08.003

98. Lang J, Yang N, Deng J, Liu K, Yang P, Zhang G. Inhibition of SARS Pseudovirus Cell Entry by Lactoferrin Binding to Heparan Sulfate Proteoglycans. PloS One (2011) 6:e23710. doi: 10.1371/journal.pone.0023710

99. Kaito M, Iwasa M, Fujita N, Kobayashi Y, Kojima Y, Ikoma J. Effect of Lactoferrin in Patients With Chronic Hepatitis C: Combination Therapy With Interferon and Ribavirin. J Gastroenterol Hepatol (2007) 22:1894-7. doi: 10.1111/j.1440-1746.2007.04858.x

100. Kruzel ML, Harari Y, Chen CY, Castro GA. Lactoferrin Protects Gut Mucosal Integrity During Endotoxemia Induced by Lipopolysaccharide in Mice. Inflammation (2000) 24:33-44. doi: 10.1023/A:1006935908960

101. Razak A, Hussain A. Lactoferrin Supplementation to Prevent Late-Onset Sepsis in Preterm Infants: A Meta-Analysis. Am J Perinatol (2021) 38 (3):283-90. doi: 10.1055/s-0039-1696676

102. Passali D, Damiani V, Cianfrone F, Passali GC, Bellussi LM, Ciprandi G. Lactoferrin: A Potential Candidate to Fight Respiratory Infections in the Pandemic COVID-19 Era. J Biol Regul Homeost Agents (2021) 35(1 Suppl. 2):9-13. doi: 10.23812/21-1supp2-3

103. Jeffery LE, Burke F, Mura M, Zheng Y, Qureshi OS, Hewison M, et al. 1,25Dihydroxyvitamin D3 and IL-2 Combine to Inhibit T Cell Production of Inflammatory Cytokines and Promote Development of Regulatory T Cells Expressing CTLA-4 and Foxp3. J Immunol (2009) 183(9):5458-67. doi: 10.4049 /jimmunol.0803217 
104. D’Avolio A, Avataneo V, Manca A, Cusato J, De Nicolò A, Lucchini R, et al. 25-Hydroxyvitamin D Concentrations Are Lower in Patients With Positive PCR for SARS-CoV-2. Nutrients (2020) 12(5):1359. doi: 10.3390/ nu12051359

105. Baladia E, Pizarro AB, Ortiz-Muñoz L, Rada G. Vitamin C for COVID-19: A Living Systematic Review. Medwave (2020) 20(6):e7978. doi: 10.5867/ medwave.2020.06.7978

106. Razzaque MS. COVID-19 Pandemic: Can Maintaining Optimal Zinc Balance Enhance Host Resistance? Tohoku J Exp Med (2020) 251(3):17581. doi: $10.1620 /$ tjem. 251.175

107. Finzi E. Treatment of SARS-CoV-2 With High Dose Oral Zinc Salts: A Report on Four Patients. Int J Infect Dis (2020) 99:307-9. doi: 10.1016/ j.ijid.2020.06.006

108. Perera M, Khoury JEL, Chinni V, Bolton D, Qu L, Johnson P, et al. Randomised Controlled Trial for High-Dose Intravenous Zinc as Adjunctive Therapy in SARS-CoV-2 (COVID-19) Positive Critically Ill Patients: Trial Protocol. BMJ Open (2020) 10(12):e040580. doi: 10.1136/ bmjopen-2020-040580

109. Barazzoni R, Bischoff SC, Krznaric Z, Pirlich M, Singer P. ESPEN Expert Statements and Practical Guidance for Nutritional Management of Individuals With SARS-CoV-2 Infection. Clin Nutr (2020) 39(6):1631-8. doi: 10.1016/j.clnu.2020.03.022
110. Rogero MM, Leão M, Santana TM, Pimentel M, Carlini GCG, da Silveira TFF, et al. Potential Benefits and Risks of Omega-3 Fatty Acids Supplementation to Patients With COVID-19. Free Radic Biol Med (2020) 156:190-9. doi: 10.1016/j.freeradbiomed.2020.07.005

111. Shakoor H, Feehan J, Al Dhaheri AS, Ali HI, Platat C, Ismail LC, et al. Immune-Boosting Role of Vitamins D, C, E, Zinc, Selenium and Omega-3 Fatty Acids: Could They Help Against COVID-19? Maturitas (2021) 143:19. doi: 10.1016/j.maturitas.2020.08.003

Conflict of Interest: Author FP was employed by the company Velleja Research S.r.l., Milan, Italy.

The remaining authors declare that the research was conducted in the absence of any commercial or financial relationships that could be construed as a potential conflict of interest.

Copyright (c) 2021 Derosa, Maffioli, D’Angelo and Di Pierro. This is an open-access article distributed under the terms of the Creative Commons Attribution License (CC BY). The use, distribution or reproduction in other forums is permitted, provided the original author(s) and the copyright owner(s) are credited and that the original publication in this journal is cited, in accordance with accepted academic practice. No use, distribution or reproduction is permitted which does not comply with these terms. 